\title{
Readiness Study of Indonesian Women with Respect to the Transition from Printed to Digital Magazine
}

\author{
Ariani Kusumo Wardhani, Setiawan Sabana, and Ira Adriati
}

\begin{abstract}
Technology is advancing rapidly and the human being wants to make their life easier and more practical. One of the examples of the recent innovations is the format change of magazine format from printed form to digital form. This transition could pose problem to the audience, especially those who has a limited experience with electronic tablet technology. In our case, we specify the audience as Indonesian women. Femina is one of the first women's magazines in Indonesia and recently, they launched the digital format of their magazine. In this work, we performed a study of the factors that could affect the readiness of the Indonesian women with respect to the transition from printed to digital format of the magazine. From the result that we obtained, the correspondents are willing to move from printed to digital format. However technological barrier, culture, and habit are still remains the main issue for such a transition. Hence the need good in user interface so they feel comfortable to move to digital magazine. Thus, more research effort should be focused in this direction in the future.
\end{abstract}

Index Terms-Digital magazine, Indonesian women, technology transition, women magazine, user interface.

\section{INTRODUCTION}

Magazine in the form of print media is one form of mass media that have existed since long ago, thus became a part of every society. Magazine serves as a medium of information and educational tool for the community. For women in the Indonesian society, such information could be obtained from the women's magazine, ranging from the children's education, cooking, career, beauty, fashion, home life, etc. Women's magazines have been described as one of the most 'strong' print medias, with an enduring popularity and vast array of titles on offer [1].

Shahnavaz [2] reports that a technology is useful when it meets three requirements; firstly, the technology should fit in with the people and the environment where it will be used. Secondly, such a technology must be in accordance with the needs and the way of workings of the local communities in long-term perspective. Thirdly, such a technology must also pay attention and consider the suitability of educational, social, cultural, infrastructural, economic, and political aspects of the local community.

Femina magazine is one of the first and popular women's magazine in Indonesia. Such a magazine is first published in 1970 Indonesia in 1972. Femina is a weekly magazine and has a circulation of over 160,000 copies per week [3]. In response to the emerging digital era and also to reduce the

Manuscript received September 25, 2013; revised November 28, 2013.

Ariani Wardhani is with the Mercu Buana University, Indonesia (e-mail: arianiwardhani@gmail.com). usage of printed paper, in the end of last year, Femina decided to launch the digital format of the magazine, where such a magazine can be downloaded from the internet via an electronic tablet.

There are no differences between the printed and the digital version of the magazine in terms of content. However, the main differences are prominent in the design layout and navigational features. Such differences could pose problems considering the main target market of Femina are women whose occupations are either working-woman or house wife, and with marital status either married or single with age above 25 years old [4], even some of them started to read starting from printed magazine. However, our main concern in this work is on the target audience Femina women (with age between 23-40 years old). It is important for the next future for women who are ready to change magazine from printed to digital. Moreover, from a previous research [5], it is shown that the advent of digitization and online availability of content would threaten the stability of the print media. Therefore, the purpose of this study is to understand several factors that could affect the readiness of the magazine's target market with respect to the usage of electronic tablet to view the digital magazine. There are two main research questions that are posed in this study as following:

Question 1: Does our main target market (Indonesian women aged 23-40 years old) accustomed to read digital magazines using an electronic tablet?

Question 2: Does the level of comfort on using an electronic tablet affects the readers to read digital format of the magazine?

The answer of these questions will provide us with the information that could be useful for our next research which is to understand the interactive visual design of media-format transition of an Indonesian women-magazine.

\section{Data Acquisition Procedure}

To obtain the data, the experimentation procedure is described as follows: First, we showed an audience the digital format of the magazine in an electronic tablet and we let them browse and view the magazine in detail. Then, we conducted interviews with each participant and they had to fill in questionnaires as a feedback of their experience with the digital magazine. The description of the data acquisition instrument (electronic tablet + digital magazine), target audience and questionnaires are shown in the next part.

\section{A. Data Acquisition Instrument}

According to the Information technology (IT) senior manager of Femina Group, the number of download of the 
digital magazine in 2011 from Ipad tables reached 33000 times compared to the other tables of mere 8000 times [6]. Thus, we selected iPad as the data acquisition instrument. The specification of the instrument is as follows: Ipad $2^{\mathrm{TM}}$ with Dual Core Apple A5 processor, 9.7-inch screen size (screen diagonal) with resolution of $1024 \times 768$ (132ppl), weighing 607 grams. The Femina digital magazine software application is installed in the tablet and the issue that is shown to the audience is: 18/XLI 4 to 10 May 2013 [7] and the total pages of this issue are 44 pages.

\section{B. Target Audience}

We interviewed 31 women with age range between $23-40$ years old as a target market for Femina magazine. These women have read printed version of Femina. All of them are housewives, working-women or entrepreneurs. The domicile of all of the target audience is Jakarta, hence they can be classified as urban women.

\section{Questionnaires}

After each target audience (correspondent) satisfied browsing the digital magazine, we asked 9 questions. We asked the correspondent to give score for each question between 1 and 5 , where 1 is strongly shows disagreement, 3 shows doubtfulness and 5 is strong agreement. The question list is shown as follows:

- Do you familiar using an online purchase?

- After reading the digital magazine, are you considering moving from printed to digital format of Femina magazine?

- Does the digital magazine includes "easy to understand" features?

- Do you feel familiar or comfortable to read the magazine in the digital format?

- Does the digital format of the magazine and its navigational functions can be well understood?

- Do you enjoy reading the digital magazines with iPad?

- Do you find the colors in the digital format more attractive compared to the printed format?

- Is the font used on the digital format is comfortable to read?

- Is the instructions of the digital magazine is easy to understand?

From such a question list, we grouped the questions into two categories:

Category 1: Questions 1-3 are focused on answering the first research question because they are mainly questioning the level of readiness of the target audiences with the electronic equipment that bears the digital magazine.

Category 2: Questions 4-9 are focused on answering the second research question. This is because these questions are related to the effect of comfort and easy to use technology level of the electronic equipment/software so the reader can make a decision whether she will move to the digital format.

\section{RESULT AND DISCUSSION}

This study used the method of non-probability purposive sample (purposive sampling). Validity test is used to measure whether a valid or invalid questionnaires. Calculation of the validity of a questionnaire can use the Pearson correlation formula. The formula is as follows:

$$
r_{x y}=\frac{n \sum X_{i} Y_{i}-\left(\sum X_{i}\right)\left(\sum Y_{i}\right)}{\sqrt{\left\{n \sum X_{i}^{2}-\left(\sum X_{i}\right)^{2}\right\}\left\{n \sum Y_{i}^{2}-\left(\sum Y_{i}\right)^{2}\right\}}}
$$

where

- $r_{x y}=$ correlation coefficient

- $n=$ number of respondents test

- $X=$ score each item

- $Y=$ score of all respondents item trials

The criteria is compared the criteria for determine significant by comparing the t-value and t-table count. If $t$ calculate $>t$-table it can be concluded that the grain items (questions) are valid. The formula for the $t$-test used is: the $t$-value and $t$-table count. If $t$ calculate> $t$-table it can be concluded that the grain items (questions) are valid. The formula for the $t$-test used is:

$$
t_{\text {calculate }}=\frac{r_{x y} \sqrt{(n-2)}}{\sqrt{\left(1-r_{x y}^{2}\right)}}
$$

TABLE I: RESULT OF INTERVIEWS FROM CATEGORY 1 QUESTIONS $(Q 1-Q 3)$

\begin{tabular}{cccc}
\hline \hline & $Q 1$ & $Q 2$ & $Q 3$ \\
\hline$r_{x y}$ & 0.67 & 0.67 & 0.63 \\
$t$-calculate & 4.81 & 4.91 & 4.38 \\
$t-$ table $(95 \%, 29)$ & 1.70 & & \\
Status & Valid & Valid & Valid \\
\hline \hline
\end{tabular}

Table I shows the interview result for Category 1 questions which are aimed to answer the first research question: The average result of the first question group is valid. Correlation test that correspondents know that digital magazine in electronic is accustomed to read, which is tablet $\mathrm{t}$ calculate $>\mathrm{t}$ table. This shows that in agree, the majority of the correspondents have some experience in using iPad. However, some of the people still do not feel comfortable in using tablet technology due to their familiarity with the printed format of the magazine. This can also explain that although the usage of daily life electronic apparatus (e.g. television, microwave and personal computer) could provide experience to the user, apparently not everyone can adapt to the format transition (in our context - printed to digital magazine format) easily. The education level apparently affects the easiness of digital technology usage. The domination of the iPad for reading digital magazine is linked with the level of education. Their relatively low level on education mostly causes the correspondents that are uncomfortable with the electronic tablet usage. Moreover, technological gaps between generations can be the main issue for our target audience. This is because they already felt comfortable with their previous habit, thus reluctant to learn using new technologies. Young people have been the forefront in new information technology usage and they remain at the top spots on internet usage statistics. In addition, they distinguish themselves as early adopters of internet features/applications such as instant messaging, peer-to-peer file sharing, and social networking tools [7]. 
TABLE II: RESULT OF INTERVIEWS FROM CATEGORY 2 QUESTIONS ( $Q 4$ -

\begin{tabular}{ccccccc}
\multicolumn{7}{c}{$Q 9)$} \\
\hline \hline & $Q 4$ & $Q 5$ & $Q 6$ & $Q 7$ & $Q 8$ & $Q 9$ \\
\hline$r_{x y}$ & 0.16 & 0.67 & 0.80 & 0.82 & 0.30 & 0.61 \\
$t-$ calculate & 0.87 & 4.82 & 7.27 & 7.75 & 1.69 & 4.15 \\
$t-$ table $(95 \%, 29)$ & 1.70 & & & & & \\
Status & Not & Valid & Valid & Valid & Not & Valid \\
& valid & & & & valid & \\
\hline \hline
\end{tabular}

Table II shows the interview result for Category 2 questions which are aimed to answer the second research question: The average result of the second question group is valid. Subsequent correlation test as valid as $t$ count $>t$ table so that the need for testing on user interface because in question 4 and 8 are not valid. In general, most of the correspondents agreed that the digital format of the magazine is as attractive as the printed format and only one correspondent still found the printed format more attractive compared to the digital one, thus found it is less attractive. From layout and features point of view, some of the correspondent does not feel familiar with the digital format. However, this is not related to the attractiveness of the magazine itself but mostly due to the technological barrier. Some people are not accustomed with navigating through digital magazine on a computer tablet. In addition, the layout in digital format is different compared to the printed ones. This is because in digital format, Femina magazine is using vertical scrolling feature to view another page for one article compared to a spread-page feature in the printed ones (Please refer to Fig. 1 and Fig. 2). Reading digital magazine in a computer tablet gave a new experience for some correspondents in this target audience thus produce unfamiliarity feeling. However, it is also interesting to note that according to most of the correspondents the digital magazine look more attractive compared to the printed format.

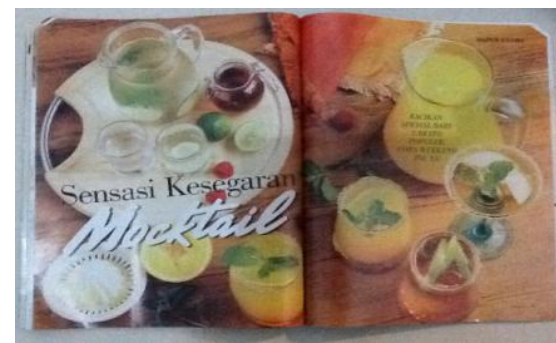

Fig. 1. Layout in printed magazine (courtesy of Femina magazine).

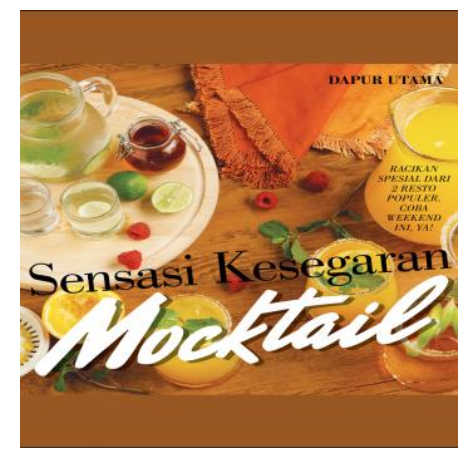

Fig. 2. Layout in digital magazine (courtesy of Femina digital magazine).

Fig. 1 and Fig. 2 shows the comparison of the layout between print and digital format of the magazine respectively. Both layouts are made with different concept for a same image. However, the media have differently format and size. For printed media, the size is $21.4 \mathrm{~cm} \times 28.4 \mathrm{~cm}$ (already trimmed) while the iPad tablet screen is 9.7 inch screen size. The resulting layout for the printed magazine is as shown in Fig. 1 (as a spread-page layout or using two pages to host an image). On the other hand, in digital format, they use "fit-to-width" concept on the width of the iPad screen and uses vertical scrolling feature to see the entire image. These two different concepts produce different experience for the users.

However, the minority of the correspondent felt comfortable due to their familiarity with the digital magazine. From color point of view, the digital format has a better clarity thus more attractive compared to the printed format. In terms of font, majority of the correspondents felt uncomfortable with the font used in the digital magazine. This is because the font is too small and it cannot be enlarged. In general, majority of the correspondent stated that there are no significant differences only the difference of content per page. Apparently this condition is sufficient to reduce the experience level on some of the correspondent. Therefore, the knowledge of user experience and interactive system design are important to gain a better understanding on additional aspects that could make the readers feel comfortable in reading the magazine. Every question in this questionnaire has different weight from comfort level point of view, but all of them are important to obtain knowledge that provides preference of the user.

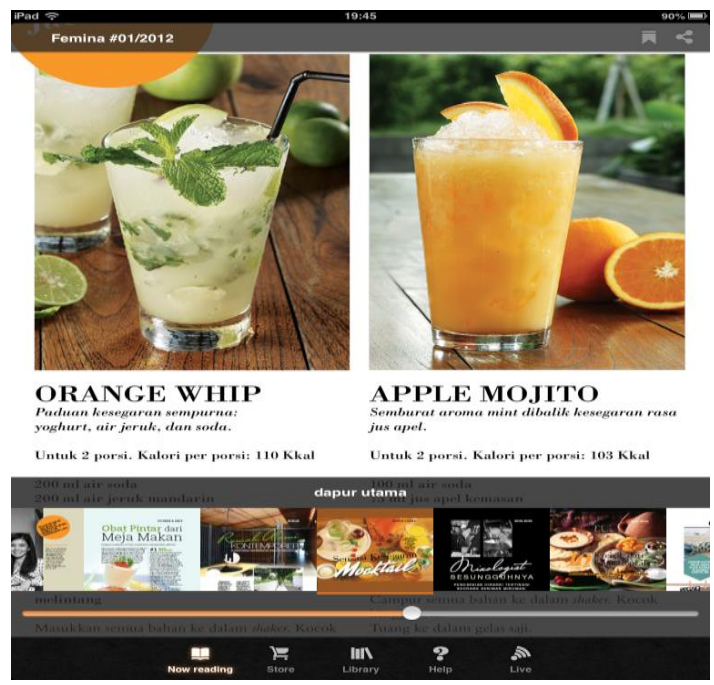

Fig. 3. Example of navigational features in digital magazine (courtesy of Femina digital magazine)

Fig. 3 shows an example of the existing navigation page on a Femina digital magazine. We can see that to choose the page to read, one can simply select and shifting the page. To go to the next page, one should shift the scroll-bar to the right while to return to the pervious page, one should shift the scroll-bar to the left. For some people who are used to read the printed version of the magazine, this feature is a new experience and could be daunting, thus inhibits their willingness to move to the digital version of the magazine.

A central concern of Femina digital magazine is to develop interaction design that is usable. By this is generally meant easy to learn, effective to use, and providing an enjoyable user experience. Part of the process of understanding readers 
is to be clear about the primary objective of developing an interactive product for them [9]. According to Marcus [10], appearance design for determine optimum minimum variations of visual and verbal attributes are one of recommendations under user interface design terms referred to earlier. Visual attributes include layout, icons and symbols, typography, color, and general aesthetics. Verbal attributes include language, formats, and ordering sequence [10].

\section{CONCLUSION}

Overall, all of the correspondent still like Femina magazine, which they have read before the digital version. The development and change in technology pushes the correspondents to learn in using the new technology. From the age factor, it is shown that the correspondents that are younger than 40 years old are more familiar to read the digital format. For some people, although they still want to follow the technological development by reading the digital magazine, their experience is reduced by the unfamiliarity of the technology. Therefore, Femina digital magazine needs to focus in interactive design to make they readers more easy to use and comfortable to change from printed to digital magazine. From the result that we obtained in this study, it shows that our target audience (Indonesian women with age between 23 and 40 years old) are interested to move to the digital version of Femina magazine from the printed ones although some people still inconvenient to read the digital. However, the knowledge to bridge such a transition (for example: understanding the most comfortable layout for the reader) is required to ascertain a smooth transition, thus more researches in this direction for interaction design and user experience are needed.

\section{REFERENCES}

[1] E. Saner. (October 2010). Women's magazine sector is bullish about the future. The Guardian. [Online]. 11. Available: http://www.guardian.co.uk/media/2010/oct/11/womens-magazines-bu llish-future

[2] H. Shahvanaz, "Macroergonomics consideration in technology transfer," in Macroergonomics, Theory, Methods and Aplications, H.W. Hendrik and B.M. Kleiner (Eds.), New Jersey: Lawrence Erlbaum Associates Publishers, pp. 311-322, 2002.

[3] Media Kit of Femina Magazine, Executive Summary Presentation Femina, Group for Femina Magazine, 2012.

[4] Presentation Femina, Media Kit Femina, 2012

[5] E. Norval, Research into Women's Magazines and the Social Construction of Womanhood, University of Leeds, 2011.

[6] Information technology senior manager of Femina Group, Personal Interview, 2013.

[7] Appstore store Femina Indonesia FMN318/2013

[8] M. Xenos and K. Foot, Not Your Father's Internet: The Generation Gap in Online Politics, University of Wisconsin and University of Washington, 2008.

[9] R. S. Preece, "What is interaction design?" in Interaction Design, Beyond Human-Computer Interaction $3^{\text {rd }}$ Edition, UK: Wiley, 2011, pp. $18-20$.

[10] A. Marcus, "Global and intercultural user-interface design," in The Human-Computer Interaction Handbook, Jacko and Sears, New Jersey London, 2003, pp. 446.

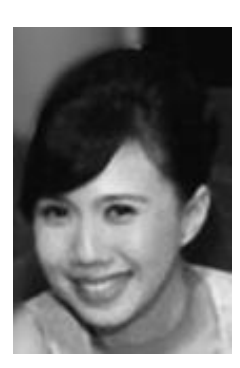

Ariani Kusumo Wardhani is a post graduate at faculty of art and design in Institut Teknologi Bandung, Bandung - Indonesia. She was born in Bandung on July 24, 1980. She obtained her bachelor of art in Design of Visual Communication from Trisakti University, Jakarta - Indonesia. Subsequently, she obtained her master degree in Digital Media from University of Sydney. In addition of being a doctoral candidate, she is also working as a lecturer at Mercu Buana University in the field of Graphic Design and Multimedia. Her research interests are including media, arts, design, and media studies. 